to provide extremely valuable information as to the chronological interrelation of the various ancient cultures, particularly as it was probable that stratified remains would be discovered.

These prognostications, it is stated in a preliminary report on the first season's excavation of the mound issued by the Carnegie Institution (Bult., 4, 6), have been strikingly verified. Even so far as operations have proceeded up to the present, it is evident that occupation of the mound was far more prolonged then had been thought probable. The mound presents resemblances to the third of the four sequent stages in the tentative classification of the culture of the lowland eity of Uaxactun, the oldest site yet excavated in the Maya area. This would bring Kaminaljuya at least down to the Old Empire; but finds from the site also present resemblances to those from Teotihuacan, the Toltec city in the Valley of Mexico.

Not only, then, does the evidence of the finds from Kaminaljuya reduce Dr. Lothrop's inference to proved fact, but it also has provided the stratified remains which Dr. Kidder desired. Quite apart, however, from their importance as evidence for cultural sequence, the finds are of an exceptional intrinsic interest. Not the least surprising result of the investigation was that after two pyramids superimposed upon a third had been revealed, still another was found beneath the third. Each of the outer three showed certain differences. The two outer pyramids, for example, rose to a surmounting platform by terraces, the third (reckoning here, as elsewhere, from the interior outward) showing three levels, whereas the second rises steeply in a single slope, and still carries a balustrade of twelve steep steps, while this feature in the third pyramid had been torn away when it was dismantled for the building of the fourth.

In examining the place of the stairway in the third pyramid, three tombs were brought to light; and a fourth, still unexamined, was found under the staircase of the second pyramid. The burials in the three tombs, which have been opened, have produced a wealth of objects, personal ornaments in jade, crystal and other material, pottery, including some remarkable painted ware, obsidian spear-heads, and other funerary offerings, which when more carefully examined at leisure will certainly throw much new light on Maya art, burial customs and culture generally.

The tombs were great square pits, vertically sided, dug in the volcanic deposit, and measuring twelve feet square and twelve feet deep. Originally they were roofed with logs, which, when found, had rotted away and let down stones and earth on the contents. An interesting feature of these tombs is the arrange. ment of the body, which, with attendant circumstances, suggests the interment of a high priest or ruling chief. In the first tomb the personage interred had been placed in a sitting position in the centre of the floor. On three sides of the skeleton lay single human skulls and on the fourth the skull of a jaguar. In the second (Tomb III) the principal skeleton was that of a middle-aged male. The body had again been placed in the middle of the tomb in a sitting posture with the legs crossed. It had been loaded with ornaments, and at the side wos a heap of pottery, in which were two human effigies in clay. At the feet of the skeleton lay the bones of a young woman and vessels for serving food, a milling stone for grinding corn, and other utensils. In a corner were the bones of a small dog. With the principal personage of the third tomb (Tomb II) were two others, possibly slaves. All were in the sitting position, facing south. This was in some ways the richest tomb of all and contained many unique pieces of pottery.

Dr. Kidder suggests in connexion with the burials, basing his opinion upon the evident character of the interment, that the custom of building pyramids superimposed one upon another may have been due to the custom of demolishing the pyramid, of which the deceased had charge at the time of his death, and preparatory to building another for his successor.

\title{
Developments in British Telegraph Services
}

\begin{abstract}
IN a paper read to the Institution of Electrical Engineers on November 19 by L. H. Harris, E. H. Jolley and F. D. Morrell, details are given of many of the engineering developments which have taken place in the inland telegraph service of the British Isles during the last few years.

It is now clear to engineers that the use of under. ground cables solely for direct current telegraphy is wasteful and that modern developments in amplifiers and filters enable a direct current cable to carry many more circuits. In 1929, the international council (C.C.I.T.) standardized the speed of the teleprinter, and two years later the spacing of the carrier frequencies to be used for voice-frequency telegraph working was also standardized. In 1931 the Post Office installed and operated a London-Dundee 12-channel system, developed and manufactured in Great Britain, which met completely the requirements laid down by the C.C.I.T. A year later the London-Glasgow-Belfast 18-channel system was installed. The introduction of demand telephone
\end{abstract}

trunk working created a shortage of trunk telephone circuits and it was decided to convert practically the whole of the inter-urban telegraph network to voice-frequency working. The telegraph cables thus thrown idle were used for telephone purposes. The number of voice-frequency telegraph channels has doubled during the last three years. The revolution in the methods used in telegraphy has been very thorough. By 1934 scarcely an item of traditional telegraph plant remained in the inland service.

Cable companies, news agencies and newspapers make considerable use of these circuits for speeds up to 100 words per minute. Voice-frequency channels are nearly always used, and even such important circuits as direct extensions of Atlantic cables are employed in this way. An increasing number of newspaper companies now rents telephone circuits on which they provide or rent equipment for alternative speech or pictures and multi-channel voicefrequency telegraphy. 
The telex service, which gives the alternative of teleprinter working to speech over the telephone network, as distinct from a separate teleprinter exchange system, has also progressed. One of the latest developments of the private teleprinter services has been the introduction of broadcast systems. In these, facilities are provided and maintained, up to the limit of the number of machines at the central office, by which the renter can transmit simultaneously to any reasonable number of outstations. News agencies and police services are finding these methods very useful.

The $\mathbf{3} 8$ frequencies used by the carrier currents in the voice-frequency channels are the odd multiples of 60 cycles from 420 to 2,460 . The currents are generated by a multi-frequency machine, driven by a motor fitted with a centrifugal governor which regulates the field current and controls the speed to within \pm 0.25 per cent. Great progress has been made in standardizing 80 volts for all telegraphic purposes, and in eliminating the 24,40 and 120 volts employed for local and main-line batteries when direct current was used. The maintenance of the voice-frequency network is carried out by the ordinary repeater-station staff, who rapidly have become familiar with the new methods. The average duration of interruptions of commercial circuits due to causes which can be attributed to the voice-frequency method do not exceed five minutes per week. In the case of private wire renters, they report faults directly by telephone using the voice-frequency terminal.

It has not been found necessary to make use of sub-audio (infra-acoustic) circuits in the British Isles, except for a few cases in which submarine cables are involved. The London-Jersey duplex teleprinter circuit is one of these cases. It is in series (composited) with the Channel Islands telephone circuit consisting of a single core unloaded submarine cable. Two duplex teleprinter circuits have been installed in the continuously loaded submarine telephone cable between Blackpool and Port Erin (Isle of Man). These circuits are noteworthy as they use only seven volts for transmission so as to avoid the risk of affecting the loading material used in the cable. Neglect of this gives rise to 'cross-talk' due to minute changes in the inductance.

The difficulties experienced at first in maintaining teleprinter speeds constant have been overcome, The difference in the speeds now seldom exceeds one per cent. The speed is checked by means of stroboscopes and synchroscopes. The latter instruments have been found to be much the more accurate. In the case of telephony, voice-frequency signalling methods and improvements in transmission technique have led to development in the direction of extending the automatic system to include the trunk circuits. This avoids the delays and costs of intermediate operating. Similarly in telegraphy, the elimination of probably 50 per cent of the operating transactions and delays would be possible by means of through automatic switching from the sending to the receiving office. The present voice-frequency network makes a framework for such a scheme which would have been quite impracticable under the old physical line conditions.

Telegraphy is now in a position to share in the rapid advances recently made in the telephone field. The teleprinter with its typewriter keyboard, the elimination of the distance factor by voice-frequency methods and the cheaper private wire telegraphic rentals should prove a boon to the commercial world.

\section{Humboldt's Plan in 1836 for a World Magnetic Survey}

4 ARLY in 1836 Alexander von Humboldt sent a 1etter to the Duke of Sussex, as president of the Royal Society, inviting the co-operation of the Society in the organization of a world magnetic survey. The letter was referred to Christie and Airy, whose report was read to the Royal Society on November 24, 1836. As von Humboldt's suggestions had a great influence on the steps afterwards taken, a few extracts from the report are given here :

"In this letter," said Christie and Airy, "M. de Humboldt developes a plan for the observation of the Phenomena of Terrestrial Magnetism worthy of the great and philosophic mind whence it has emanated and one from which may be anticipated the establishment of the theory of these phenomena. . . The Baron de Humboldt and MM. Arago and H. Kupffer having, by the co-operation of many zealous observers, succeeded in establishing permanent magnetic stations extending from Paris to China, M. de Humboldt solicits, through His Royal Highness the President, the powerful influence of the Royal Society in extending the plan by the estab. lishment of new stations. The plan which he proposes ... is that magnetical observations, whether of the direction of the horizontal and inclined needles, or for the determination of the variations of the magnetic force, should be made simultaneously at all stations, at short intervals of time, for a certain number of hours and at fixed periods of the year precisely similar to the plan which has been recom. mended and adopted by Sir John Herschel with reference to observations of the barometer and thermometer." He also "considers that it deeply interests the advancement of mathematical and physical sciences that, under the auspices of His Royal Highness the President, the Royal Society should exert its influence in extending the line of simultaneous observations, and in establishing permanent magnetic stations in the tropical regions on both sides of the equator, in high southern latitudes and in Canada. . . . Should the proposition meet with their concurrence he begs that the Royal Society will enter into direct communication with the Royal Society of Göttingen, the Royal Institute of France and the Imperial Academy of Russia, to adopt the most proper measures to combine what is proposed to be established with what already exists".

After a full review of the subject, Christie and Airy went on to say, "By referring to M. de Humboldt's letter, it will be seen that the plan of observation so comprehensively conceived by him, has been most powerfully and liberally patronized by the Governments of France, of Prussia, of Hanover, of Denmark and of Russia ; indeed it is quite manifest that a plan so extensive in its nature must be far beyond the means of individuals, and even of scientific societies, unaided by the governments under which they flourish. . . . To suppose . . . that the Government of this, the first maritime and commercial nation of the globe, should hesitate to patronize such an undertaking ... would imply that our Government is not alive either to the interests or to the scientific character of the country, and would show that we had little attended to the history, even in our own time, of scientific research, which has been so liberally promoted by the Government. . . We therefore feel assured that, when 